\title{
Increased village potential towards creative and independent communities
}

\author{
Yuan Alfinsyah Sihombing ${ }^{1}$, Ester Rinaldi Hulu ${ }^{2}$, Tini Ayuna Hutabarat ${ }^{3}$, Tasha Juliana \\ Puspitasari $^{4}$ \\ ${ }^{1}$ Faculty of Mathematics and Natural Science, Universitas Sumatera Utara \\ ${ }^{2}$ Faculty of Public Health, Universitas Sumatera Utara \\ ${ }^{3}$ Faculty of Culture, Universitas Sumatera Utara \\ ${ }^{4}$ Faculty of Agriculture, Universitas Sumatera Utara \\ *Email: yuanalfinsyah@yahoo.com
}

\begin{abstract}
Community service activities are divided into three stages, namely preparation, implementation of activities on site, and evaluation. These community service activities have been carried out in Pematang Marihat Village, Siantar Marimbun District, Pematangsiantar City in the form of health check-up activities namely blood sugar and blood pressure checks, health education, healthy exercise, PHBS which is specialized in dental and mouth hygiene, hands and nails, reactivation hydroponics, planting vegetable seeds in polybags, making Family Medicinal Plants (TOGA), making compost from straw, learning groups and teaching activities in schools. The implementation of these activities is expected to benefit the local community. Get closer to the relationship of higher education with the community where KKN students are located. Train students in studying social phenomena that occur in the community. Providing space and land for students to express their application of theories that have been obtained on campus to become agents of change in society. The activities carried out in support of these activities are morning activities, healthy exercise, non-communicable disease counseling, health and clean lifestyle counseling, blood sugar and blood pressure checks, reactivation of hydroponics, Family Medicinal Plant Manufacturing (TOGA), compost fertilizer production from straw. With the completion of the work program of KKN (Real Work Lecture) Group 2 Pematang Marihat Village, Siantar Marimbun District, Pematangsiantar City, the translation of the Tri Dharma of Higher Education to the community can be carried out well. Through the implementation of this Community Service Program, we can apply the knowledge gained in college in the form of community service in Pematang Marihat Village.
\end{abstract}

Keyword: Potential, Counseling, Coaching

\begin{abstract}
Abstrak
Kegiatan pengabdian KKN dibagi menjadi tiga tahap, yaitu persiapan, pelaksanaan kegiatan di lokasi, dan evaluasi. Kegiatan pengabdian masyarakat ini telah dilaksanakan di Kelurahan Pematang Marihat, Kecamatan Siantar Marimbun, Kota Pematangsiantar berupa kegiatan pemeriksaan kesehatan yaitu cek gula darah dan tekanan darah, penyuluhan kesehatan, senam sehat, PHBS yang dikhususkan pada kebersihan gigi dan mulut, tangan dan kuku, pengaktifan kembali hidroponik, penanaman bibit sayur di polibag, pembuatan Tanaman Obat Keluarga (TOGA), pembuatan pupuk kompos dari jerami, kelompok belajar dan kegiatan mengajar di sekolahsekolah. Pelaksanaan kegiatan-kegiatan tersebut diharapkan dapat bermanfaat bagi masyarakat setempat. Mendekatkan relasi perguruan tinggi dengan masyarakat dimana mahasiswa KKN berada. Melatih mahasiswa dalam mengkaji fenomena-fenomena sosial yang terjadi di lingkungan masyarakat. Memberikan ruang dan lahan bagi mahasiswa untuk berekspresi mengaplikasikan teori yang telah didapatkan di kampus untuk menjadi agen perubahan dalam masyarakat. Adapun kegiatan yang dilaksanakan dalam mendukung kegiatan ini yaitu Giat pagi, senam sehat, penyuluhan penyakit tidak menular, penyuluhan pola hidup bersih dan sehat, pemeriksaan gula darah dan tekanan darah, pengaktifan kembali hidroponik, Pembuatan Tanaman Obat Keluarga (TOGA), pembuatan pupuk kompos dari jerami. Dengan rampungnya program kerja mahasiswa KKN (Kuliah Kerja Nyata) Kelompok 2 Kelurahan Pematang Marihat, Kecamatan Siantar Marimbun, Kota Pematangsiantar, maka penjabaran Tri Dharma Perguruan Tinggi kepada masyarakat dapat terlaksana dengan baik. Melalui pelaksanaan KKN ini kami dapat mengaplikasikan pengetahuan yang didapat di bangku kuliah dalam bentuk pengabdian kepada masyarakat di Kelurahan Pematang Marihat.
\end{abstract}

Kata Kunci: Potensi, penyuluhan, pembinaan 


\section{PENDAhuluan}

Program Kuliah Kerja Nyata (KKN) merupakan salah satu program Universitas Sumatera Utara sebagai implementasi Tri Dharma Perguruan tinggi yaitu pengabdian mahasiswa terhadap masyarakat untuk membantu dan membimbing masyarakat dalam memanfaatkan sumber daya yang diharapkan serta mengembangkan potensi masyarakat. Program ini dilaksanakan dengan menyelaraskan kegiatan riset dan pengabdian kepada masyarakat dari dosen dan mahasiswa lintas keilmuan serta tetap membawa nilai-nilai kebersamaan USU. Atas dasar itulah maka kami kelompok mahasiwa yang ditempatkan di Kecamatan Siantar Marimbun, Kelurahan Pematang Marihat berkewajiban bersama-sama dengan warga desa merealisasikan substansi dari KKN tersebut sesuai dengan judul KKN yaitu "Pemberdayaan Kearifan Lokal dan Potensi Desa Menuju Masyarakat Cerdas, Kreatif, dan Mandiri di Kota Pematang Siantar, Kecamatan Siantar Marimbun, Kelurahan Pematang Marihat, Provinsi Sumatera Utara".

Pematangsiantar adalah sebuah Kota yang terletak di Provinsi Sumatra Utara, Indonesia. Dengan Ibu kota yang terletak di Pematangsiantar. Kota Pematangsiantar terletak pada garis $2^{\circ} 53^{\prime} 20^{\prime \prime}-3^{\circ} 01^{\prime} 00^{\prime}$ ' lintang utara dan $99^{\circ} 1^{\prime} 00^{\prime \prime}-99^{\circ} 65^{\prime}$ " bujur timur, berada ditengah-tengah wilayah Kabupaten Simalungun. Luas Daratan Pematangsiantar adalah $79,971 \mathrm{~km}^{2}$ yang mana terletak 400-500 meter di atas permukaan laut. Kelurahan Pematang Marihat memiliki jumlah penduduk sebesar 3.102 jiwa yang mana jumlah penduduk berjenis kelamin laki-laki sebesar 1.549 jiwa dan jumlah penduduk berjenis kelamin perempuan sebesar 1.553 jiwa. Terdapat 12 RT, 4 RW dan 2 Kepling (Kepala Lingkungan) di Kelurahan Pematang Marihat dan terdapat beberapa sekolah diantaranya, TK Swasta Subuluh Salam, PAUD Kelurahan Pematang Marihat, MTS Ibnu Sina, SMP Negeri 11, dan MAS Ibnu Sina. Terdapat Puskesmas Bah Biak sebagai fasilitas kesehatan di Kelurahan Pematang Marihat. Adapun mata pencaharian penduduk adalah bertani dan wiraswasta.

Dengan potensi-potensi yang disebutkan diatas membuat Kelurahan Pematang Marihat memprioritaskan pengembangan potensi pertanian yang cukup mengingat mayoritas penduduk disana berprofesi sebagai petani dan pemanfaatan pekarangan rumah.

\section{METODE PELAKSANAAN}

Metode sosialisasi, yakni metode atau cara yang dilakukan mahasiswa dalam berintraksi dengan masyarakat Pematang Marihat berupa komunikasi langsung dan tidak langsung. Bentuk sosialisasi tersebut misalnya.

a. Dialog dengan pemuda-pemudi kelurahan pematang marihat.

b. Mengikuti ibadah di gereja dan juga di masjid bersama warga setempat Dari kegiatan tersebut diharapkan dapat input data berbagai prihal permasalahan yang terdapat di wilayah tersebut yang dapat ditangani khususnya pada rana budaya.

\section{HASIL DAN PEMBAHASAN}

a. Giat Pagi

Giat pagi adalah suatu aktivitas rutin yang dilakukan TIM bersama petugas kebersihan setempat yang bertugas untuk membersihkan rumput-rumput di pinggir jalan raya. Kegiatan ini dilakukan pagi hari dimulai pada pukul 08.30-10.00 WIB. Peralatan kebersihan diperoleh dari kelurahan dan masyarakat setempat. 


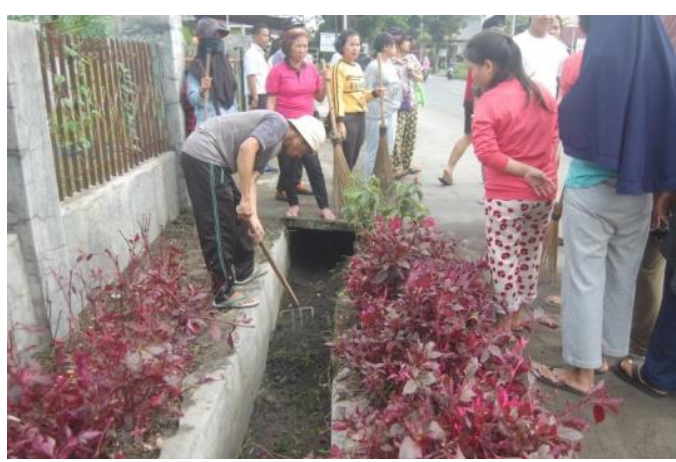

Gambar 3.1. Suasana giat pagi

b. Senam Sehat

Senam lansia dilakukan setiap hari selasa pagi di sekitaran rumah warga. Senam ini terdiri dari pemanasan, inti, dan pendinginan. TIM ikut berpartisipasi sebagai peserta senam bersama para lansia. Kegiatan ini terlaksana atas kerjasama TIM dengan pihak Puskesmas Bah Biak.

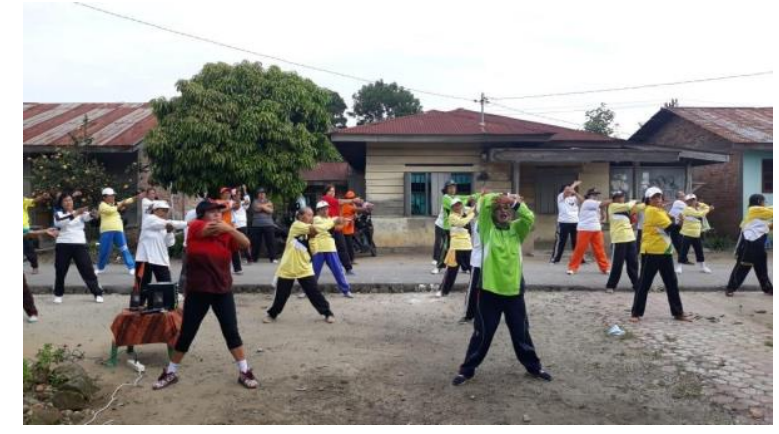

Gambar 3.2. Suasana giat pagi di pekarangan warga

c. Penyuluhan Penyakit Tidak Menular

Penyuluhan dilakukan setelah kegiatan senam dilakukan, baik senam lansia maupun senam bersama ibu PKK dan warga. Senam sebagai sarana untuk bertemu dengan masyarakat dan melakukan penyuluhan kesehatan seperti penyuluhan penyakit tidak menular dan jamban sehat. Penyuluhan jamban sehat dilakukan karena beberapa warga masih menggunakan sungai untuk membuang hajat dengan alasan tidak memiliki jamban di rumah.

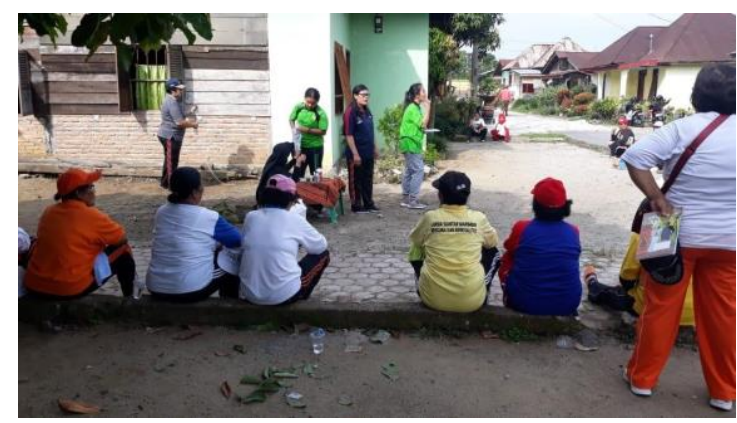

Gambar 3.3. Suasana saat penyuluhan berlangsung 
d. Penyuluhan Pola Hidup Bersih dan Sehat

Penyuluhan PHBS yang dilakukan oleh TIM adalah mengenai kebersihan mulut dan gigi, tangan dan kuku. Kegiatan ini dilakukan di sekolah dan PAUD sebagai kegiatan untuk merayakan Hari Anak Nasional yang jatuh pada tanggal 23 Juli. Untuk menambah ketertarikan siswa terhadap pola hidup sehat dan bersih, TIM menggunakan media musik berupa lagu 6 langkah cuci tangan dan sikat gigimu.

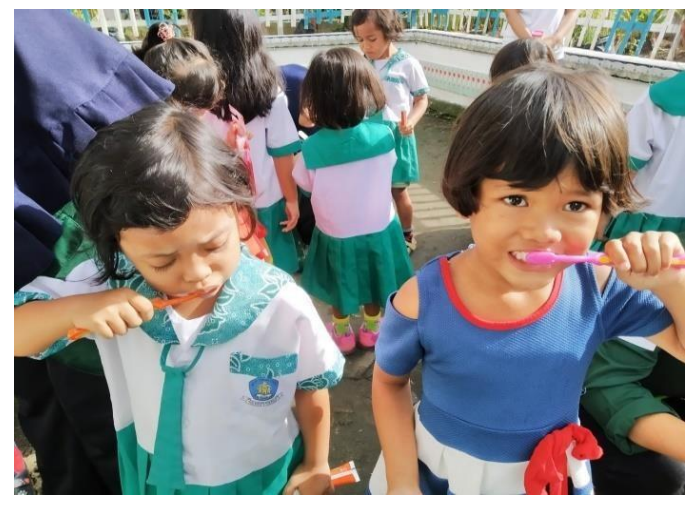

Gambar 3.4. Menyikat gigi sebagai salah satu PHBS

e. Pemeriksaan Gula Darah dan Tekanan Darah

Pemeriksaan gula darah dan tekanan darah dilakukan pada masyarakat setelah kegiatan senam dan penyuluhan berlangsung. Kegiatan ini dilakukan secara bertahap dimulai dengan pemeriksaan gula darah lalu dilanjutkan dengan pemeriksaan tekanan darah. Pelaksanaan pemeriksaan kesehatan ini berlangsung atas kerjasama TIM dengan pihak Puskesmas Bah Biak. Tujuan dari pemeriksaan kesehatan ini supaya masyarakat rutin untuk memeriksa kesehatan serta melakukan pola hidup yang sehat.

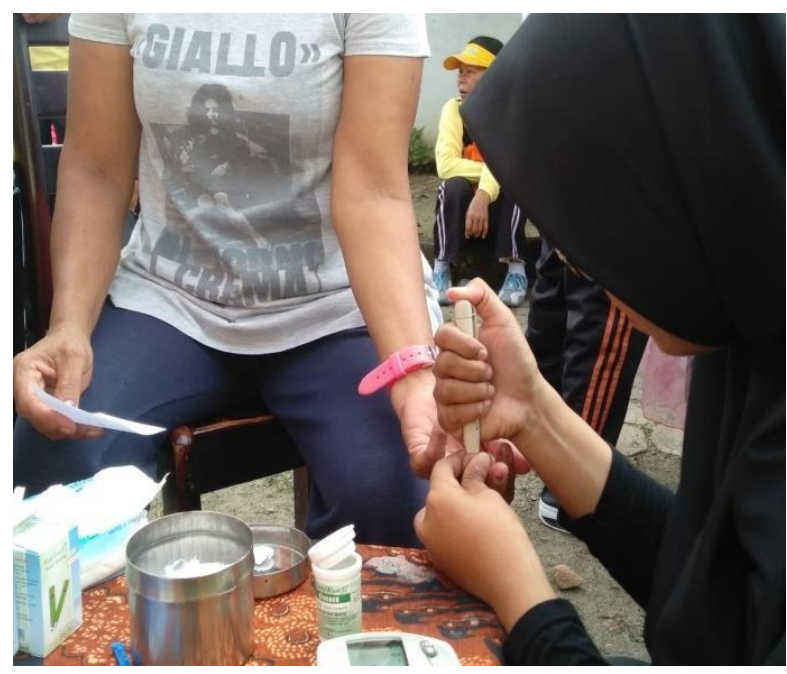

Gambar 3.5. Pemeriksaan gula darah

f. Pengaktifan kembali hidroponik

Kegiatan ini dilakukan dengan mengunjungi rumah-rumah warga yang memiliki hidroponik, dimulai pada tanggal 26 Juli 2019. TIM melakukan diskusi terhadap warga terkait hidroponik yang tidak digunakan lagi dan memberikan sosialisasi penggunaan hidroponik yang baik dan 
benar. Terlebih dahulu TIM menanam benih untuk dijadikan bibit pada hidroponik dan melakukan simulasi pada 1 hidroponik.

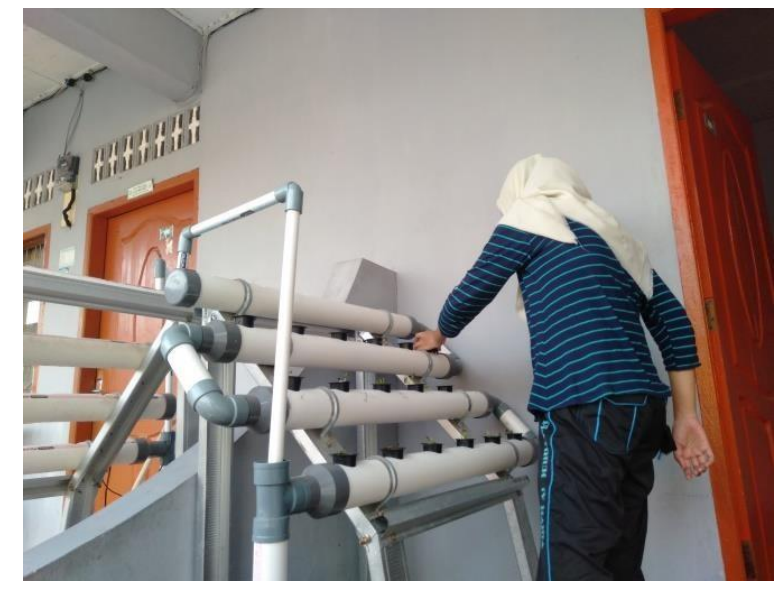

Gambar 3.6. Peletakan bibit pada hidroponik

g. Pembuatan Tanaman Obat Keluarga (TOGA)

Tanaman obat keluarga merupakan tanaman hasil budidaya rumahan yang berkhasihat sebagai obat. Pembuatan tanaman obat keluarga di Kelurahan Pematang Marihat bertujuan agar warga dapat dengan mudah menemukan obat-obat herbal. Kegiatan ini dilakukan selama 2 hari dibantu oleh petugas kebersihan dan PKK Pematang Marihat, yang mana TIM melakukan pembersihakan lahan, penanaman dan penamaan tanaman obat, serta pembuatan plank untuk TOGA.

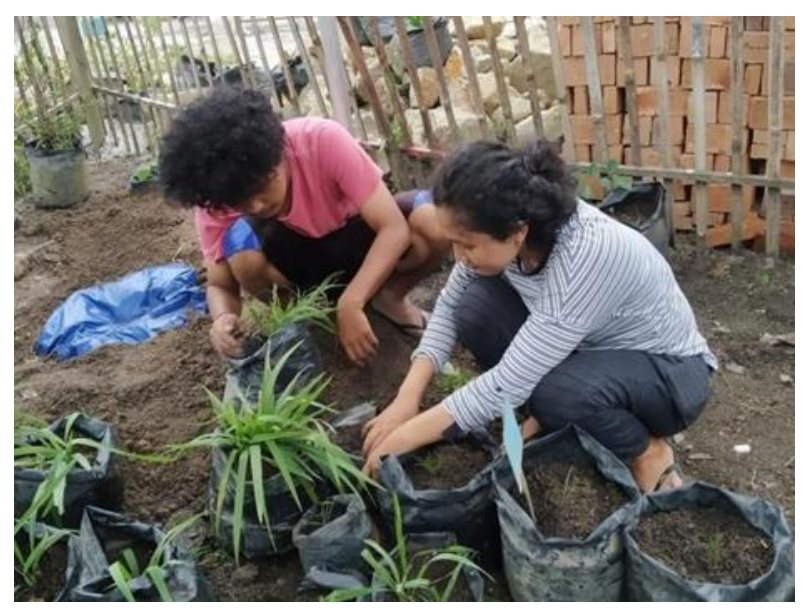

Gambar 3.7. Penanaman kembali daun bawang batak

h. Pembuatan Pupuk Kompos Dari Jerami

Masyarakat di Kelurahan Pematang Marihat sebagian besar berprofesi sebagai petani. Dengan demikian TIM melakukan diskusi ke beberapa petani terkait pengelolaan limbah jerami. Pengelolaan limbah yang kurang baik oleh petani membuat TIM mensosialisasikan mengenai pembuatan pupuk kompos dari jerami. Pembuatan pupuk ini dilakukan dengan 2 metode, yaitu disimpan pada drum tertutup dan disimpan di galian tanah dengan menggunakan terpal sebagai alas dan penutup jerami. 


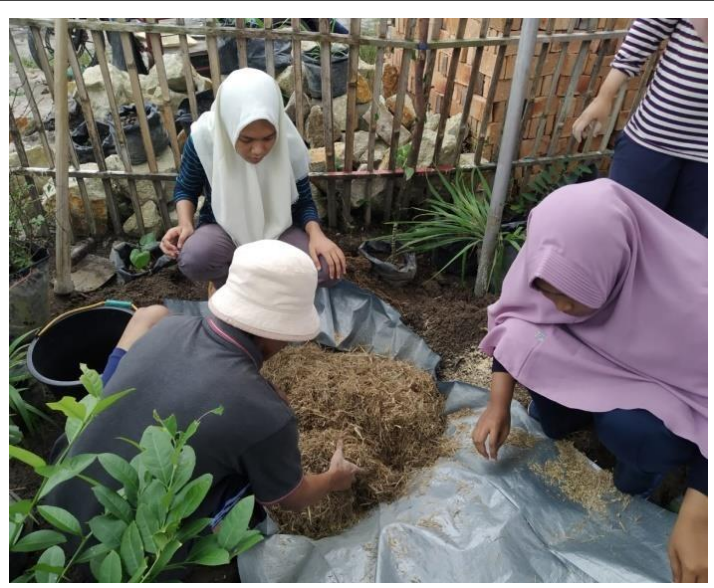

Gambar 3.8. Pencampuran jerami dengan bakteri EM-4 yang telah dicampur air

\section{KESIMPULAN}

Dengan rampungnya program kerja mahasiswa KKN (Kuliah Kerja Nyata) Kelompok 2 Kelurahan Pematang Marihat, Kecamatan Siantar Marimbun, Kota Pematangsiantar, maka penjabaran Tri Dharma Perguruan Tinggi kepada masyarakat dapat terlaksana dengan baik. Melalui pelaksanaan KKN ini kami dapat mengaplikasikan pengetahuan yang didapat di bangku kuliah dalam bentuk pengabdian kepada masyarakat di Kelurahan Pematang Marihat.

\section{UCAPAN TERIMAKASIH}

Ucapan Terima Kasih kepada Lembaga Pengabdian kepada Masyarakat Universitas Sumatera Utara yang telah Menfasilitasi Pelaksanaan Pengabdian Masyarakat IbM Mono Tahun (Dosen Muda)

\section{DAFTAR PUSTAKA}

Badan Pusat Statistik Kota Pematangsiantar. 2016. Kota Pematangsiantar dalam Angka, Pematangsiantar City in Figure 2016. Pematangsiantar: BPS Kota Pematangsiantar.

Damanik, Dani Boy. 2017. Implementasi Kebijakan Sistem Pelayanan Informasi dan Perizinan Investasi Secara Elektronik (SPIPISE) di Dinas Penanaman Modal dan Pelayanan Terpadu Satu Pintu (DPMPTSP) Kota Pematangsiantar. Skripsi. Medan: Departemen Ilmu Administrasi Publik, FISIPOL USU.

Kaya, E. 2013. Pengaruh Kompos Jerami dan Pupuk NPK terhadap N-Tersedia Tanah, Serapan-N, Pertumbuhan dan Hasil Padi Sawah. Agrologia. Vol: 2, No: 1, pp. 43-50.

Pangaribuan, Darwin dan Hidayat Pujisiswanto. 2008. Pemanfaatan Kompos Jerami untuk Meningkatkan Produksi dan Kualitas Buah Tomat. Prosiding Seminar Nasional Sains dan Teknologi-II 2008. Universitas Lampung, 17-18 November 2008.

Rosliani, Rini dan Nani Sumarni. 2005. Budidaya Tanaman Sayuran dengan Sistem Hidroponik. Bandung: Balai Penelitian Tanaman Sayuran.

Santoso, Hieronymus Budi. 1998. TOGA 2 - Tanaman Obat Keluarga. Yogyakarta: Penerbit Kanisius. 